\title{
E-learning During COVID-19 in a Medical College
}

\author{
Hanan I. Almuzaini, MD * \\ Department of Otorhinolaryngology \& Head and Neck Surgery, Faculty of Medicine, Taibah University, \\ Madinah, 30001, Saudi Arabia \\ * Corresponding Author: Dr. Hanan I. Almuzaini; dr.hanan.almuzaini @ gmail.com
}

Received 05 September 2021;

Accepted 21 September 2021;

Published 01 October 2021

\begin{abstract}
Recently, many medical schools shifted from live lectures to online lecture by reducing classic lectures with using more technology. E-learning increased all over the world during the period of the spread of the COVID-19 virus. In addition, it is important to know if such learning strategies are advantageous. This will help institutions consider how to distribute their funding resources for platform design and online learning.
\end{abstract}

Keywords: E-learning, medical schools, COVID-19

\section{Review of literature}

In unusual and extraordinary occasions, we exist. As the 2019 coronavirus disease (COVID-19) pandemic has interrupted many activities in the world. The pandemic outbreak prompted many restrictions on moving homes, commuting, shopping, exercise, access to essential public services, including childcare or schooling, medical and social services, medical education has also been disrupted. While preventing an outbreak and providing patient care is the main priority of medical educators, who are also healthcare professionals, medical education also needs intensive focus during this time ${ }^{[1,2]}$.

Coronavirus disease (COVID-19) has internationally impacted on medical education, it has been affected, with seminars, clinical placements and main exams halted. Our concern in all medical college. What is the best way of teaching, and what resources will be there to provide education? As well as how to be more prepared for any future circumstances that could disrupt clinical practice and in-person interaction. These initiatives have contributed to a sudden change in methods of teaching towards online teaching ${ }^{[3,4]}$.

Over the past decade, we have seen that e-learning has become increasingly popular in teaching and learning in medical education. We expect more integration of online teaching methods within conventional medical education beyond COVID-19. The observed change in medical practice towards virtual consultations could be followed by this ${ }^{[3]}$.

E-learning is also called Web-based learning, online learning, distributed learning, computer-assisted teaching, or Internet-based learning. Two popular e-learning modes have traditionally existed: distance learning and computer-assisted instruction. Distance learning uses information technology to offer guidance from a central site to learners who are in remote locations. Computer-assisted instruction (also referred to as computer-based learning and computer-based training) uses computers to assist in providing learning and teaching stand-alone multimedia packages ${ }^{[4,5]}$.

E-learning content in each Subject depend on the learning objects are separate, self-contained units of instructional material assembled and reassembled around specific learning objectives that are used to create larger educational materials to meet the specifications of a given curriculum, such as classes, modules, or complete courses. Examples include instances of Tutorials, case-oriented instruction, hypermedia, simulations, and learning modules based on sports. The distribution of content can either be synchronous or asynchronous. Synchronous delivery applies to e-learning in real-time, instructor-led, where all learners receive data simultaneously and connect directly with other learners. For example, teleconferencing (audio, video, or both), internal teleconferencing, messaging immediately. With distribution asynchronous, there is no simultaneous transmission and reception of information. The learners are responsible for timing and practicing their own self-instruction. Using e-mail or feedback technologies, the teacher and learners connect, but not in real time. For asynchronous distribution, a range of techniques, like email, online message boards, listservs, newsgroups, and weblogs, may be used ${ }^{[5]}$.

Kyong-jee Kim in has study illustrates the current popularity among medical students is online videos as learning resources. In the near future, the widespread use of online videos is likely to continue, as they play an important role in clinical education. It is also probable that the creation and use of educational videos in medical education is becoming more common with the Growing social media popularity ${ }^{[6]}$. This also highlighted the possible role of the social media to enhance medical education, as illustrated in surgical training ${ }^{[3]}$. 
Differences in the popularity of learning resources across subjects were also noticed. Between online videos, users more frequently watched clips on procedural skills than those on patient experiences and video lectures. In addition, the level of use of online videos on procedural skills across content domains also differed. These differences could reflect the learning requirements for medical students to complement conventional clinical skills instructions, especially those that are not readily available for direct observation or those that demonstrate somewhat complex procedural skills. In clinical cases, there have also been variations in the frequency of use, and there may be many explanations for that. Some cases likely fit more closely with the core curriculum and some of the content may be outside the context of basic medical education ${ }^{[6]}$. Compared to the discussion forums and the supplementary materials, the video lectures and the assignments were found to be the most important and contributing learning resources ${ }^{[7]}$.

Online courses make many changes in pattern of interactions between students and their professors. One of this changes e.g in online courses, students can participate from any location at any hour of the day in online classes. The flexibility could allow students to manage time and effort more efficiently, but it could also be a challenge for students who have not learned to manage their own time. Professors and students do not interact face-to-face; they only interact through written communication that is asynchronous. Students are therefore likely to feel less oversight from their professors and less pressure to respond to questions from professors. In the standard principal-agent problem, the agent's (student) effort falls as it becomes less visible to the main agent (professor). The professor's role is quite markedly different. Inputs are standardized by online classes, traditionally varying between professors. Lectures are replaced with videos, for example. The variation in student outcomes between professors may shrink or widen depending on how professors choose to use the time saved by not lecturing ${ }^{[8]}$.

There are many Advantage of E-learning here we mention some of them; Delivery of learning is the most commonly benefits which requires Increased information accessibility, Simple content updating, Material standardization, and Accessibility. Accessibility extends to the capacity of the consumer to find what is required, when it's needed. It is simpler to update electronic content than to update written content. E-learning technologies allow educators to simply and quickly review their materials. Learners have control over the content, the sequence of learning, the speed of learning, time, and allow them to achieve their personal learning goals. Another strength of e learning is that it standardizes the content and delivery of the course; unlike, for example, a lecture given to distinct parts of the same course. Automated monitoring and documentation of the activities of learners reduces the administrative burden of the faculty. In addition, e-learning may be structured to involve assessing findings to assess if learning has occurred. Learning enhancement allows for greater interactivity of learners and promotes the effectiveness, motivation, cognitive effectiveness, and learning style flexibility of learners. Interactive learning shifts the focus from a passive model centered on teachers to one that is active and learner-centered, offering a stronger stimulus for learning. Interactivity helps to retain the interest of the learner and provides a means for individual practice and strengthening. Evidence suggests that elearning is more effective because learners gain knowledge, skills, and attitudes more quickly than traditional techniques led by teachers. This effectiveness is likely to translate into improved performance and motivation. Increased retention rates and better use of content have been shown by e-learners, resulting in better achievement of knowledge, skills, and attitudes. Multimedia Elearning offers learners the flexibility to choose from a wide range of media options to accommodate their various styles of learning ${ }^{[5]}$.

When the Advantages of E-learning are mentioned, the cost of E-learning teaching must be addressed. Compared with traditional instructor-led learning, E-learning will result in substantial cost savings, often as much as 50 percent. The savings are attributed to decrease preparation time for teachers, travel and labour expenses, reduced institutional infrastructure and the prospect of extending programs with new educational technology. They also found that printing and delivery of instructional materials was less expensive than producing and disseminating content for e-learning ${ }^{[5]}$. Sharing e-learning resources between institutions are likely to saving money ${ }^{[9]}$.

In Other hand E-Learning has also disadvantages: It seems that the biggest barriers to online teaching are Family distractions, the connection to the Internet and the timing of Tutorials. This may be disadvantageous for learners with large families, or with restricted access to the Internet ${ }^{[8]}$. Additional the mental health of student in current situation of COVID-19 has adversely impacted on E-learning and unfair judgment on it ${ }^{[3]}$. Prevalence and levels of stress and anxiety increased, and symptoms of depression persisted unaltered during the outbreak and quarantine of COVID-19 ${ }^{[10]}$. Psychological and learning behaviors of these medical students, the long-term quarantine due to COVID-19 pandemics could cause further deterioration ${ }^{[11]}$. Female had higher anxiety level than male in among medical school $^{[12]}$.

We recommend that medical schools resort to educational formats to optimize the benefits of both face-to-face and online teaching and to increase the effectiveness of medical education in the future. This uses online teaching platforms to encourage students to absorb knowledge in their own time, but also to allow students to discuss this content with peers constructively. In terms of achieving learning results, it has been shown to be effective ${ }^{[3]}$. Students have used e-learning resources on their learning platform more times than other online resources .This is certainly this guarantees clarity of knowledge and accuracy, and reduces inconsistencies, as there are no differences comparing to other web-based learning sites ${ }^{[13]}$.

The design principles of interactive learning content, learning objectives and the needs and features of students should be rigorously evaluated in order to guarantee the efficacy of online learning ${ }^{[13,14]}$. It may be worthwhile to combine the benefits of online and offline teaching methods, called blended learning, to avoid the possible disadvantages of online learning in undergraduate medical education ${ }^{[14]}$.

Online Assessment is also important tools in higher education and part of E-learning without fear of losing academic rigor or jeopardizing student performance. The outcome of Miguel Ardid's analysis of various application methodologies in online assessment for blended evaluation was 1-The absence of differences between online and offline assessment conducted under similar conditions; 2-The existence of noticeable differences between assessments in proctored and unproctored environments; 3-The online exam has a high discriminatory power, although the cut may depend on the methodology used in the assessment ${ }^{[15]}$. Amanda J. Meyer, reported about Student Performance on Practical Gross Anatomy Examinations is not affected by the mode of gross anatomy examination and the majority of students had positive perceptions of either mode online or laboratory ${ }^{[16]}$. 
The evaluation of e-learning should include a peerreview process and an assessment of outcomes such as learner satisfaction, content usability, and demonstration of learning ${ }^{[5]}$.

A recent systematic analysis indicated that, in terms of exam results, offline teaching and online teaching are equivalent ${ }^{[3]}$. Anjeela Jokhan illustrated that there is no statistical significant difference in the total marks of the students in the two modes in the Faculty of Science, Technology and Environment, it can be concluded that the performance of students in the two modes is similar and that students in the online mode are faring as well as students in the face-to-face mode ${ }^{[17]}$. The results showed that the students were very satisfied with the online courses and that most of them were interested in participating in future online courses ${ }^{[7]}$. Many medical students have also been reported to find e-learning enjoyable ${ }^{[4]}$.

Although not all the studies reported that using online learning mode was more effective than offline learning, but none of them concluded that online learning was less effective than offline methods ${ }^{[14]}$. In addition, in these classes, positive feelings about learning in online courses play an important role in student performance $^{[7]}$.

E-learning does not end clinical teaching but rather complements it ${ }^{[13]}$. Students do not see e-learning as a replacement for traditional instructor-led teaching, but as a compliment to it, being part of a blended learning strategy ${ }^{[5]}$.

\section{Summary}

Coronavirus disease (COVID-19) has internationally impacted on medical education. Over the past decade, we have seen that elearning has become increasingly popular in teaching. We expect more integration of online teaching methods within traditional medical education beyond COVID-19. The distribution of content can either be synchronous or synchronous. In the near future, the widespread use of online videos is likely to continue, as they play an important role in clinical education. E-learning in undergraduate student showing more efficiency and effectiveness. As well as satisfaction among Teacher and Learners.

\section{List of abbreviations}

COVID-19: Corona Virus Disease 2019

E-learning: Electronic Learning

\section{Data Availability}

Data derived from Taibah University public domain resources and available within the article.

\section{Conflicts of Interest}

There is no conflict of interest with this manuscript.

\section{Funding Statement}

The author has not received any research funding.

\section{Acknowledgment}

The author would like to thank Dr. Hany M. Abo-Haded for his for valuable research comments that helped to improve the quality of this research.

\section{Reference}

[1] Medical Education in Turkey in Time of COVID-19, by Trakya University School of Medicine, The Balkan Medical Journal published by Galenos Publishing House. Balkan Med J 2020;37:180-1, DOI:10.4274/balkanmedj.galenos.2020.2020.4.003.

[2] Examining Anxiety, Life Satisfaction, General Health, Stress and Coping Styles During COVID-19 Pandemic in Polish Sample of University Students, Aleksandra M Rogowska 1 Cezary Kuśnierz 2 Anna Bokszczanin 1, Institute of Psychology, University of Opole, Opole, Poland; 2020:13 797-811

[3] Dost S, Hossain A,Shehab M, et al. Perceptions of medical students towards online teaching during the COVID-19 pandemic: a national cross-sectional survey of 2721 UK medical students. BMJ Open 2020;10:e042378. doi:10.1136/ bmjopen-2020-042378

[4] Our education, our concerns: The impact on medical student education of COVID-19, Cara Theoret | Xue Ming, Rutgers New Jersey Medical School, Newark, New Jersey, USA, Department of Neurology, Rutgers New Jersey Medical School, 90 Bergen Street, DOC 8100, Newark, New Jersey 07101, USA.

[5] The Impact of E-Learning in Medical Education, Jorge G. Ruiz, Michael J. Mintzer, and Rosanne M. Leipzig, Acad Med. 2006; 81:207-212.

[6] Development of e-learning in medical education: 10 years' experience of Korean medical schools, Kyong-Jee Kim and Giwoon Kim, Department of Medical Education, Dongguk University School of Medicine, Goyang and 2Department of Emergency Medicine, Soonchunhyang University Bucheon Hospital, Soonchunhyang University College of Medicine, Bucheon, Korea Korean J Med Educ 2019 Sep; 31(3): 205-214.

[7] E-assessment of online academic courses via students' activities and perceptions,Tal Soffer*, Tali Kahan, Eynat Livne School of Education, Tel Aviv University.

[8] Virtual Classrooms: How Online College Courses Affect Student Success, By Eric P. Bettinger, Lindsay Fox, Susanna Loeb, and Eric S. Taylor, American Economic Review 2017, 107(9): 2855-2875

[9] The future of e-learning in healthcare professional education: some possible directions, Kieran Walsh, Ann Ist Super Sanit. 2014 | Vol. 50, No. 4: 309-310, DOI:10.4415/ANN_14_04_02

[10] Impact of COVID-19 outbreak on the mental health status of undergraduate medical students in a COVID-19 treating medical college: a prospective longitudinal study, Ilango Saraswathi, DOI 10.7717/peerj.10164

[11] COVID-19 Pandemic: Impact of Quarantine on Medical Students' Mental Wellbeing and Learning Behaviors, Sultan Ayoub Meo1, doi: https://doi.org/10.12669/pjms.36.COVID19-S4.2809

[12] Conspiracy Beliefs Are Associated with Lower Knowledge and Higher Anxiety Levels Regarding COVID-19 among Students at the University of Jordan, Malik Sallam, Int. J. Environ. Res. Public Health 2020, 17, 4915.

[13] Development of e-learning in medical education: a student's perspective, Nour Al Jamil, Korean J Med 
Educ 2019 Dec; 31(4): 371-373., https://doi.org/10.3946/kjme.2019.147

[14] Does online learning work better than offline learning in undergraduate medical education? A systematic review and meta-analysis, Leisi Pei \& Hongbin Wu, MEDICAL EDUCATION ONLINE 2019, VOL. 24, 1666538, https://doi.org/10.1080/10872981.2019.1666538

[15] Online exams for blended assessment. Study of different application methodologies, Miguel Ardid, Computers \& $\begin{array}{llll}\text { Education } & 81 & \text { (2015) }\end{array}$ http://dx.doi.org/10.1016/j.compedu.2014.10.010

[16] Student Performance on Practical Gross Anatomy Examinations is not Affected by Assessment Modality, Amanda J. Meyer, Anat Sci Educ 9:111-120 (2016)

[17] Are students studying in the online mode faring as well as students studying in the face-to-face mode? Has equivalence in learning been achieved?, Aluwesi Volau Fonolahi, MERLOT Journal of Online Learning and Teaching Vol. 10, No. 4, December 2014 (c) (i)

Open Access This article is licensed under a Creative Commons Attribution 4.0 International License, which permits use, sharing, adaptation, distribution and reproduction in any medium or format, as long as you give appropriate credit to the original author(s) and the source, provide a link to the Creative Commons license, and indicate if changes were made. The images or other third party material in this article are included in the article's Creative Commons license, unless indicated otherwise in a credit line to the material. If material is not included in the article's Creative Commons license and your intended use is not permitted by statutory regulation or exceeds the permitted use, you will need to obtain permission directly from the copyright holder. To view a copy of this license, visit https://creativecommons.org/licenses/by/4.0/.

(c) The Author(s) 2021 